Arkivoc

Free to Authors and Readers
A Platinum Open Access Journal for Organic Chemistry

Paper

DOAJ Seal
Arkivoc 2021, part vi, 86-100

\title{
Synthesis of poly(vinyl ether)s by chain-end capping with a silyl ketene acetal in $a b$ initio cationic polymerisations
}

\author{
Prodip Sarker, ${ }^{a}$ Weihong Lang, ${ }^{a}$ Rami Obaid, ${ }^{a}$ and Stephen Rimmer ${ }^{b}$ \\ ${ }^{a}$ Department of Chemistry, University of Sheffield, Sheffield, South Yorkshire, UK, S3 7HF \\ ${ }^{b}$ Polymer and Biomaterials Chemistry Laboratories, School of Chemistry and Biosciences, University of \\ Bradford, Bradford, West Yorkshire, UK, BD7 1DB \\ E-mail: s.rimmer@bradford.ac.uk
}

Received 04-16-2021

Accepted Manuscript 05-19-2021

Published on line 06-04-2021

\section{Abstract}

Inclusion of a silyl ketene acetal in the non-living cationic polymerisations of methyl and isobutyl vinyl ether provides polymers with ester end groups. The use of an $a b$ initio approach produces materials with high degrees of chain end functionality provided the reaction temperature, monomer concentration and concentration of silyl ketene acetal are optimised. Optimisation, studied mainly by the use of MALDI-ToF mass spectrometry, involved obtaining reaction conditions in which the dominant termination reaction was alkylation of the silyl ketene acetal then rapid desilation produced the ester end groups.

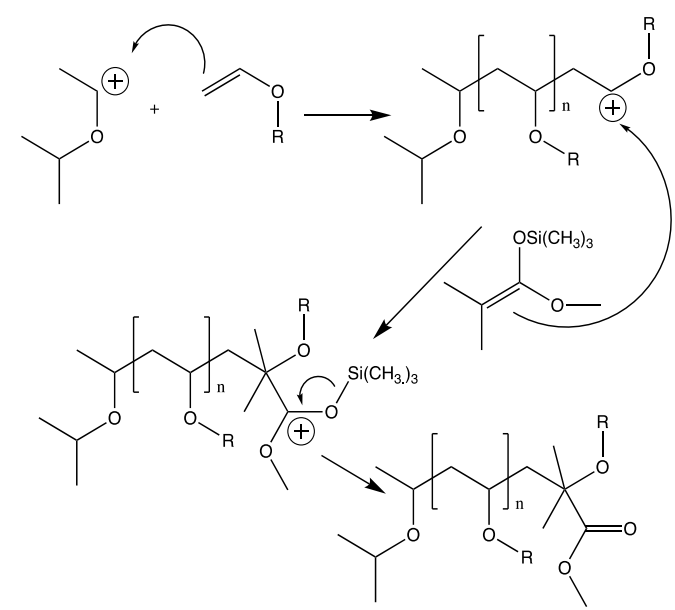

Keywords: Cationic polymerisation, vinyl ether, silyl ketene acetal, ester end group 


\section{Introduction}

End functional polymers are ubiquitous in many important established technologies (e.g. adhesives and paints.) and the newer emergent technologies (drug delivery, controlled release etc.). They are precursors to a wide variety of classes of materials including polymer networks, ${ }^{1}$ polymer brushes ${ }^{2,3}$ and block copolymers. ${ }^{4}$ The end groups can provide interesting solution and bulk properties. ${ }^{5}$ In step growth polymerisations the required chain end functionality can easily be added by stopping the polymerisation at moderate extent of reaction or by carrying out polymerisations at non-equivalent stoichiometry. On the other hand, addition of end group functionality in chain growth polymerisations requires control of the termination processes. During radical chain growth polymerisation chain end functionality can be added in a number of ways: by capping the chains produced in controlled polymerisations; using transfer processes or by controlled cleavage of high molecular weight polymers. ${ }^{6}$ In ionic polymerisations the only generally practiced method is the chain end capping of sequential living polymerisations, which requires the propagating chain end to remain active until a functional terminating agent is added in a separate step. ${ }^{7-12}$ However, an alternative method uses the discovery that, in both the cationic polymerisation of vinyl ethers and conventional radical polymerisations, it was possible to add species (silyl enol ethers), which terminate the propagating chain and add chain end functionality simultaneously with propagation. ${ }^{13-16}$

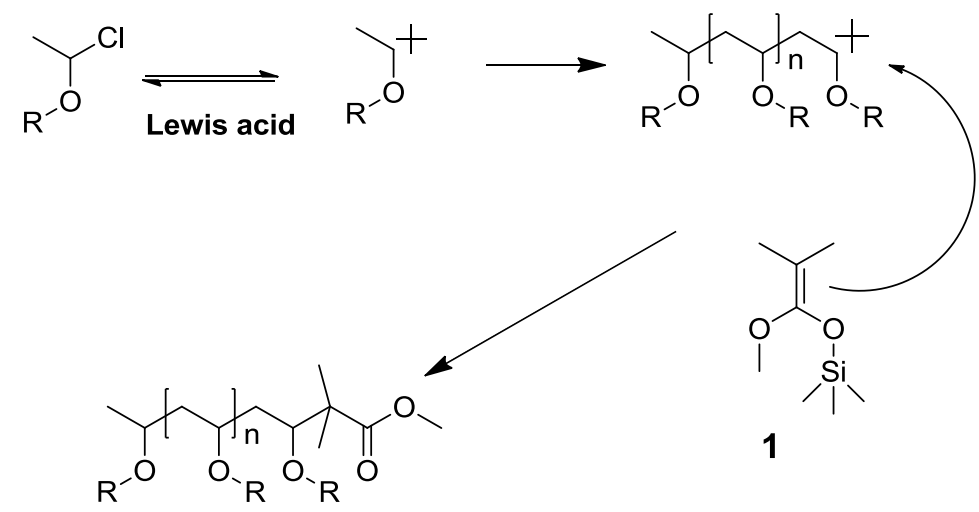

Scheme 1. Polymerisation of vinyl ethers in the presence of 1-methoxy-2-methyl-1-(trimethylsilyloxy)propene, (1).

In cationic polymerisations we used the term $a b$ initio cationic polymerisation to distinguish these polymerisations from living cationic polymerisation approaches that involve addition of the nucleophilic capping agent after propagation had finished. ${ }^{13}$ The method has the advantage, in that it is applicable to polymerisations with short cation or radical lifetimes: i.e. the chain capping reaction competes with the normal termination reactions and occurs on the same timescale as propagation so that living polymerisation is not required. Optimisation of these polymerisations produced polymers with essentially $100 \%$ of the chain end functionality produced by the alkylation of the added silyl enol ether. In the case of the use of silyl enol ethers Sawamoto et al had previously shown that the reaction of silyl enol ethers at the end of living cationic polymerizations produced polymers with the same high degree of chain end functionality but their use of living polymerizations required careful control of reactant purity, exclusion of water, etc. ${ }^{17-21}$ Chain-end capping to provide polymers with useful end group functionality was recently reviewed by Tasdelen et $\mathrm{al}^{22}$ and as far as we are aware there is only one example of the use of the reactions of silyl ketene acetals with polymer carbcocations in chain capping reactions involving living polymerizations of vinyl ethers. ${ }^{21}$ The $^{2}$ 
alkylation of silyl ketene acetals with carbocations produces esters ${ }^{23-25}$ that would be of general utility in the production of polymers with a wide variety of useful end groups. Also, silyl ketene acetals are highly nucleophilic and the reactivity scales produced by Mayr indicated that they would have suitable rate constants for use as terminating agents during $a b$ initio cationic polymerisation. ${ }^{24,25}$ Therefore, in this work we report that the modification of the cationic polymerizations of vinyl ethers, methyl vinyl ether (MVE) and isobutyl vinyl ether (iBVE) with a commercially available silyl enol ketal, 1-methoxy-2-methyl-1-(trimethylsilyloxy)propene, 1, produces polymers with useful ester end groups, as shown in scheme 1. Both $\mathrm{SnCl}_{4}$ and $\mathrm{TiCl}_{4}$ have been used for the polymerisation of $i \mathrm{BVE}$ ) and they can be used as Lewis acids without additives. ${ }^{32}$ However, $^{2}$ $\mathrm{SnCl}_{4}$ living polymerisation was only observed at low concentration $\left(5 \times 10^{-4} \mathrm{~mol} . \mathrm{dm}^{-3}\right)$ and at low temperature $\left(-78{ }^{\circ} \mathrm{C}\right.$ rather than $\left.-15{ }^{\circ} \mathrm{C}\right) .{ }^{32}$ The use of $\mathrm{TiCl}_{4}$ in the polymerisation $i \mathrm{BVE}$ provided a living polymerisation at $-78{ }^{\circ} \mathrm{C}$ but MALDI-TOF mass spectrometry showed that significant transfer occurred at -15 ${ }^{\circ} \mathrm{C}$ leading to initiation by $\mathrm{H}+$. The rates of polymerisation with strong Lewis acids are often very fast and in systems that require sequential capping of living polymers the long residence time (compared to the time for propagation) of the living chain, in contact with Lewis acid but at low monomer concentration, can lead to side reactions after propagation has finished. Chain capping with agents added at the start of the polymerisation can be used to alleviate this problem because the rate of chain capping is similar to the rate of propagation and this minimises the lifetime required for the carbocationic chain end.

\section{Results and Discussion}

\section{Polymerisations of methyl vinyl ether}

Initially, polymerisations of $\mathrm{MVE}$ were attempted using $\mathrm{SnCl}_{4}$ as Lewis acid. However, typically, living polymerisation of $\mathrm{MVE}$ with $\mathrm{SnCl}_{4}$ as Lewis acid requires the use of modifiers, such as tetraalkyl ammonium salts. ${ }^{29}$ In this work no modifers were used and it was found that it was not possible to produce polymers with high degrees of chain end functionality with this Lewis acid at either -26 or $-78{ }^{\circ} \mathrm{C}$. The MVE polymers were also highly disperse in molar mass.


Figure 1. Molar mass (SEC) data for polymerisation of MVE $\left(0.6 \mathrm{~mol} \mathrm{dm}^{-3}\right)$ in the presence of 1 initiated by iBVE: $\mathrm{HCl}: \mathrm{TiCl}_{4}\left(0.05 \mathrm{~mol} \mathrm{dm}{ }^{-3}\right)$. Reaction time 1.5 hours at $-26^{\circ} \mathrm{C}$ or $-78^{\circ} \mathrm{C} \mathbf{A}$.

Following these experiments the polymerisations of MVE were carried out using $i \mathrm{BVE}: \mathrm{HCl}: \mathrm{TiCl}_{4}$ as initiator at -26 and $-78{ }^{\circ} \mathrm{C}$ in the presence of 1 . Some polymerisations were also conducted at $-15^{\circ} \mathrm{C}$ but MALDI-ToF 
mass spectrometry showed that these polymerisations produced polymers with a multitude of chain ends and no further work was carried out at this temperature.

A series of polymerisations were carried out in which the starting initiator and monomer concentrations were held constant but the concentration of 1 was varied. The data from these experiments are presented in figures 1, 2 and 3. Alkylation of silyl enol ethers during the timescale for propagation leads to a reduction in the degree of polymerisation as the concentration of the terminating agent changes. Alternatively, propagation that is much faster than alkylation is analogous to a conventional living polymerization, in which the degree of polymerisation is independent of the concentration of a capping agent. Thus, evidence for capping of the carbocationic chain end during propagation was derived from plots of molar mass against 1 , as shown in Figure 1(a) that is, at both polymerisation temperatures, molar mass decreases sharply as the initial concentration of 1 increases. In figure 1(b) Control of the termination reactions was also indicated by decreasing dispersity $\left(M_{w} / M_{n}\right)$. One factor that produces broadening in $M_{w} / M_{n}$ in a non-living cationic polymerization is the existence of several routes to chain termination. If alkylation of $\mathbf{1}$ is the dominant termination reaction the system becomes subject to a single termination rate constant, which decreases $M_{w} / M_{n}$. Figure 1(b) shows that there was a general decrease in $M_{w} / M_{n}$ as the concentration of 1 increased at both polymerisation temperatures. However, at $-26^{\circ} \mathrm{C}$ there was an increase in $M_{w} / M_{n}$ compared to the result obtained in the absence of 1 when it was added at an initiator:1 ratio of 1:1 ([1] $=0.05 \mathrm{~mol} \mathrm{dm}^{-3}$ ). Further increases in [1] lead to a substantial decrease in $M_{w} / M_{n}$. At $-78^{\circ} \mathrm{C}$ the normal termination processes led to a high value of $M_{w} / M_{n}$ in the absence of 1 . However, as expected, as [1] increased $M_{w} / M_{n}$ decreased as the rate of alkylation increased to became the dominant termination process.


Figure 2. MALDI ToF mass spectra derived from: (a) MVE polymerised at $-26^{\circ} \mathrm{C}$ (b) MVE polymerised at $-78{ }^{\circ} \mathrm{C}$ $\left([1]=0.15 \mathrm{~mol} . \mathrm{dm}^{-3}\right)$. Ion series indicated with * or \#.

It is possible to use MALDI-ToF mass spectrometry to calculate chain end functionality if it is assumed that at constant degree of polymerisation the influence of the end groups on the extent of ionisation is not significant. Figure 2(a) derived from polymerisation at $-26^{\circ} \mathrm{C}\left([1]=0.15 \mathrm{~mol} . \mathrm{dm}^{-3}\right)$ contains two series of ions, $\mathrm{m} / \mathrm{z}=\mathrm{n} 58.0+(23.0+202.3)$, which are derived from cationisation by sodium, and $\mathrm{m} / \mathrm{z}=\mathrm{n} 58.1+(23.0+$ 102.1), which are derived from the polymers with methyl-(2, 2 dimethyl) ethanoate at the $\omega$-end but the methoxy ethyl group at the $\alpha$-chain end. The latter group would be obtained from initiation by $\mathrm{H}+$ from adventitious water or from termination by elimination. The former is more likely given that the spectra do not include any series that could be assigned to polymers derived from elimination. Figure 2(b) shows a mass 
spectrum produced from a polymerisation carried out at $-78^{\circ} \mathrm{C}\left([1]=0.15 \mathrm{~mol}\right.$. $\left.\mathrm{dm}^{-3}\right)$. The dominant distribution was composed of ions separated by $\mathrm{m} / \mathrm{z} 58$ and the distribution could be described by $\mathrm{m} / \mathrm{z}=(58 \mathrm{n}$ $+23+202$ ). Thus, both spectra were derived from polymer ions with end groups that sum to $\mathrm{m} / z$ 202; i.e. 1isobutoxy ethyl at the $\alpha$-end and methyl-(2, 2 dimethyl) ethanoate at the $\omega$-end. The spectra show that polymers produced using this procedure produced almost entirely the target species and as expected there was little evidence for polymers that were initiated by $\mathrm{H}+$ at $-78^{\circ} \mathrm{C}$.
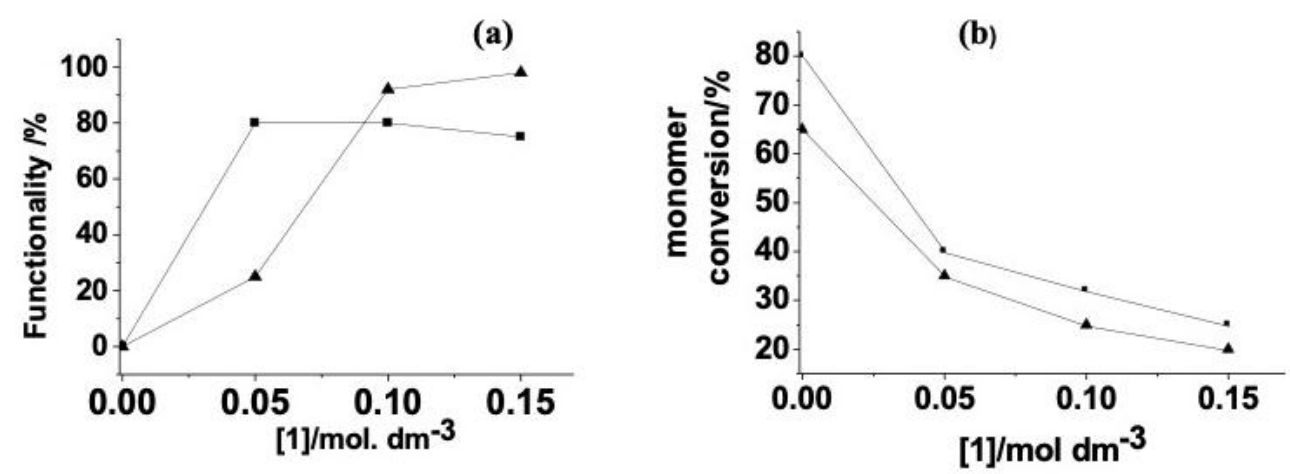

Figure 3. (a) Functionality (percentage of chain ends derived from alkylation of 1) of polyMVE prepared with various initial [1]. $-26^{\circ} \mathrm{C}$ or $-78^{\circ} \mathrm{C} \boldsymbol{\Delta}$; (b) MVE conversions after 1.5 hours prepared with various initial [1]. $26^{\circ} \mathrm{C}$ or $-78^{\circ} \mathrm{C} \boldsymbol{A}$.

Katayama et $a l^{32}$ had previously shown that polymerisation of $i \mathrm{BVE}$ initiated with $\mathrm{TiCl}_{4}$ was living at $-78{ }^{\circ} \mathrm{C}$ and the data reported here showed that the polymerisation of $\mathrm{MVE}$ using $\mathrm{TiCl}_{4} \mathrm{Could}_{\text {be }}$ modified by addition of 1 at $-78{ }^{\circ} \mathrm{C}$ to provide polymers with the target ester end groups. On the other hand as stated previously it was not possible to produced poly(MVE) with high end group functionality using $\mathrm{SnCl}_{4}$ as Lewis acid. Functionalities (ie the mole percent with $\alpha$-1-isobutoxy ethyl, $\omega$-methyl-(2, 2 dimethyl) ethanoate chain ends) were calculated from the MALDI ToF mass spectra ${ }^{15}$ and the data are presented in figure $3(a)$. At $-78{ }^{\circ} \mathrm{C}$, the polymerisations carried out at [1] $=0.05$ mol. $\mathrm{dm}^{-3}$ (1:1 molar equivalence of 1 :initiator) gave lower degrees of functionality than polymerisations run with excess 1 . However, as indicated in figure 3(a) and shown earlier in figure 2 (b) the polymerisation carried out at $-78{ }^{\circ} \mathrm{C}$ and [1] $=0.15 \mathrm{~mol} . \mathrm{dm}^{-3}$ produced chains that contained only negligible amounts of ends other than those derived from the initiator and $\mathbf{1}$. The polymerisations at -26 ${ }^{\circ} \mathrm{C}$ produced polymers that were partially functionalised by the initiator and $\mathbf{1}$ at all concentrations of 1 . The data indicated that at $-26^{\circ} \mathrm{C}$ the alkyklation of 1 was the main termination reaction but the target polymer, with 1-isobutoxy ethyl at the $\alpha$-end and methyl- $(2,2$ dimethyl) ethanoate at the $\omega$-end, was only produced in $80 \%$ yield. The other $20 \%$ of the product, as shown in figure $2 \mathrm{a}$ was derived from initiation by $\mathrm{H}+$ derived from adventitious water. At $-78{ }^{\circ} \mathrm{C}$ the alkylation of 1 dominated the termination processes in the presence of excess 1. 


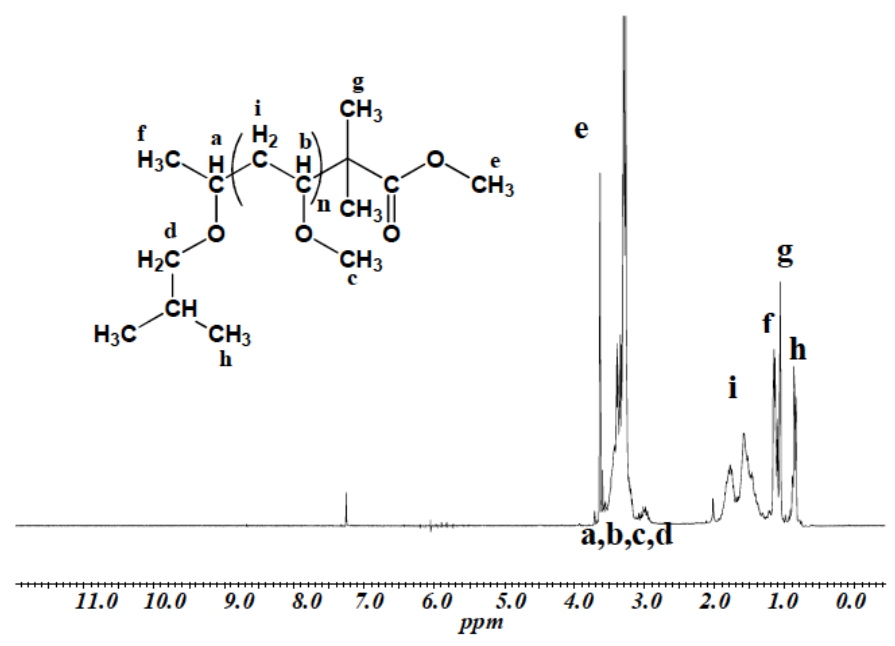

Figure 4. ${ }^{1} \mathrm{H}$ NMR spectrum of PMVE prepared at $-26{ }^{\circ} \mathrm{C}$ in the presence of 1 . Assignments at $a, b, c, d$ and $i$ are described in reference 26.

In this work one of our aims was to alleviate the need to resort to excessive purification and drying of reagents, monomers and solvents so that in this respect these polymerisations are clearly best carried out at $78{ }^{\circ} \mathrm{C}$ rather than $-26{ }^{\circ} \mathrm{C}$ because at $-26{ }^{\circ} \mathrm{C}$ adventitious water can initiate undesirable polymerisations leading to polymers with unwanted chain end functionalities. Figure 3(b) shows that as expected the increased rates of termination, which are inevitable as [1] increases, led also to a decrease in final monomer conversion. Although this is clearly a disadvantage in a batch polymerisation we consider that future developments of this method will require the use of a semi-continuous process in which initiator is replenished throughout the time course of the polymerisation. A similar approach was used by us recently in radical polymerisations carried out in the presence of a silyl enol ether. ${ }^{16}$

Figure 4 shows a representative ${ }^{1} \mathrm{H}$ NMR spectrum from a MVE polymerisation. In all of the examples of polymerisations, carried out in the presence of $\mathbf{1}$, resonances from the methyl groups at position $\mathbf{g}$ were observed at $1.05 \mathrm{ppm}$ and the methyl groups at positions $\mathbf{f}$ and $\mathbf{h}$ were observed as indicated in the figure. The methoxy group was also observed at $3.70 \mathrm{ppm}$ (e in figure 4). The peak at $\mathbf{g}$ and e were both absent from analogous polymerisations carried out in the absence of $1 .{ }^{13} \mathrm{C}$ NMR spectra also showed two resonances at 177 and 178 ppm that were assigned to the chain end ester carbonyl group.

\section{Polymerisations of isobutyl vinyl ether}



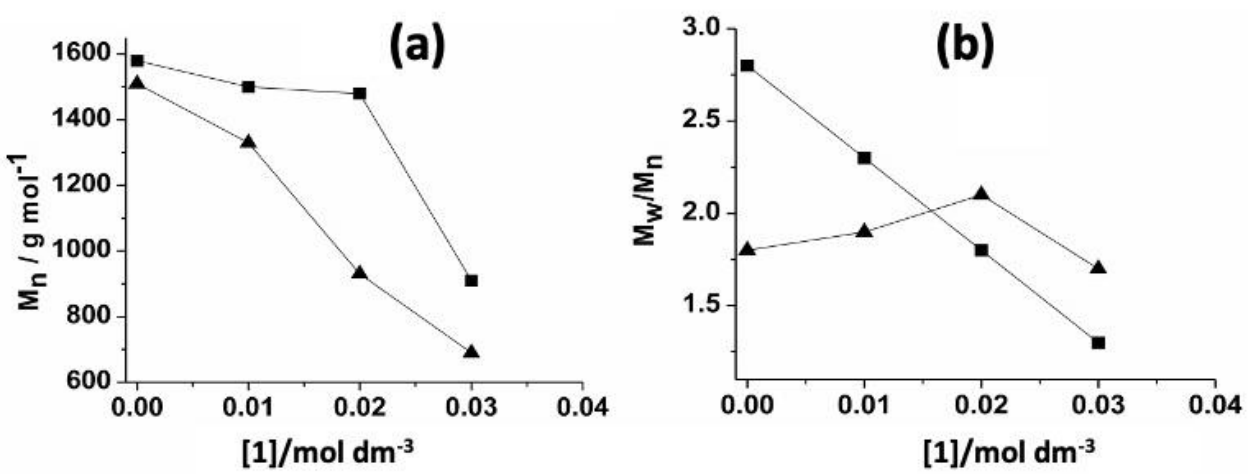

Figure. 5 Molar mass data for polymerization of $i \operatorname{BVE}\left(1.0 \mathrm{~mol} \mathrm{dm}^{-3}\right)$ in the presence of 1 initiated by iBVE: $\mathrm{HCl}: \mathrm{SnCl}_{4}\left(0.01 \mathrm{~mol} \mathrm{dm}{ }^{-3}\right)$. Reaction time 1.5 hours at $-26^{\circ} \mathrm{C} \mathbf{a}$ or $-78^{\circ} \mathrm{C} \boldsymbol{\Delta}$.

It is known that the polymerisation of MVE and other vinyl ethers progress with different rate constants for initiation propagation and termination ${ }^{27,28}$ and these differences were expected to be reflected in the results from iBVE polymerisation compared to polymerisation of MVE in the presence of 1 . Figure 5 shows molar mass data from polymerisations using $\mathrm{SnCl}_{4}$ as Lewis acid. The results show that $M_{n}$ decreased with increasing [1] at both -26 and $-78{ }^{\circ} \mathrm{C}$. Figure 5b) shows that at $-78{ }^{\circ} \mathrm{C} M_{w} / M_{n}$ increased with increasing [1] upto $0.02 \mathrm{~mol}$. dm ${ }^{-3}$ but then decreased. On the otherhand $M_{w} / M_{n}$ decreased continuously as [1] increased when the polymerisations were carried out at $-26{ }^{\circ} \mathrm{C}$. Therefore, the data provide indications that capping of the chain end occurred within the timescale of propagation but the increase in $M_{w} / M_{n}$ provided indications that multiple termination and/or initiation mechanisms were operative.

Examples of the MALDI-ToF mass spectra from polymers produced at -26 and $-78{ }^{\circ} \mathrm{C}$ are shown in figure 6 . Both spectra were composed of a dominant series of ions that were described by: 6(a), reaction temperature $26{ }^{\circ} \mathrm{C} \mathrm{m} / z=n 99.7+(23+201.7)$ and $6(b)$, reaction temperature $-78{ }^{\circ} \mathrm{C} \mathrm{m} / z=n 99.8+(23+202.7$.) The end groups of these series of ions were thus composed of the predicted $\alpha-\mathrm{H}$ and $\omega$-methyl- $(2,2$ dimethyl) ethanoate moieties. In figure $6(\mathrm{a})$ (reaction temperature $=-26{ }^{\circ} \mathrm{C}$ ) a significant secondary series of ions was observed that was described by $m / z=n 99.7+(23+74)$. The end masses of this series can be rationalised as being derived from by chain ends that were capped with $\mathrm{H}$ at $\alpha$ and isobutoxy at $\omega$, as observed in previous polymerisations with this monomer. ${ }^{30}$ In figure $6(\mathrm{~b})$ (reaction temperature $=-78{ }^{\circ} \mathrm{C}$ ) another minor series described by $m / z=n 100.0+(23+45.3)$ was observed. This mass correlates to the end groups with $\mathrm{H}$ at the $\alpha$ chain end and $-\mathrm{CH}_{2} \mathrm{CHO}$ at the $\omega$ chain end. Poly(iBVE) with $-\mathrm{CH}_{2} \mathrm{CHO}$ end group has been previously observed using MALDI ToF mass spectrometry by Katayama et al. ${ }^{31}$ Figure 7 a shows how the functionality of these polymers increased to approximately $75 \%$, as the concentration of 1 was increased. In similar polymerisations of $\mathrm{MVE}$ using $\mathrm{SnCl}_{4}$ it was only possible to produce polymers with a maximum of $60 \%$ functionality (at $-78{ }^{\circ} \mathrm{C}$ ). Clearly, this system requires further optimisation but the data do indicate that useful poly(iBVE)s with ester end groups can be produced in this way. 

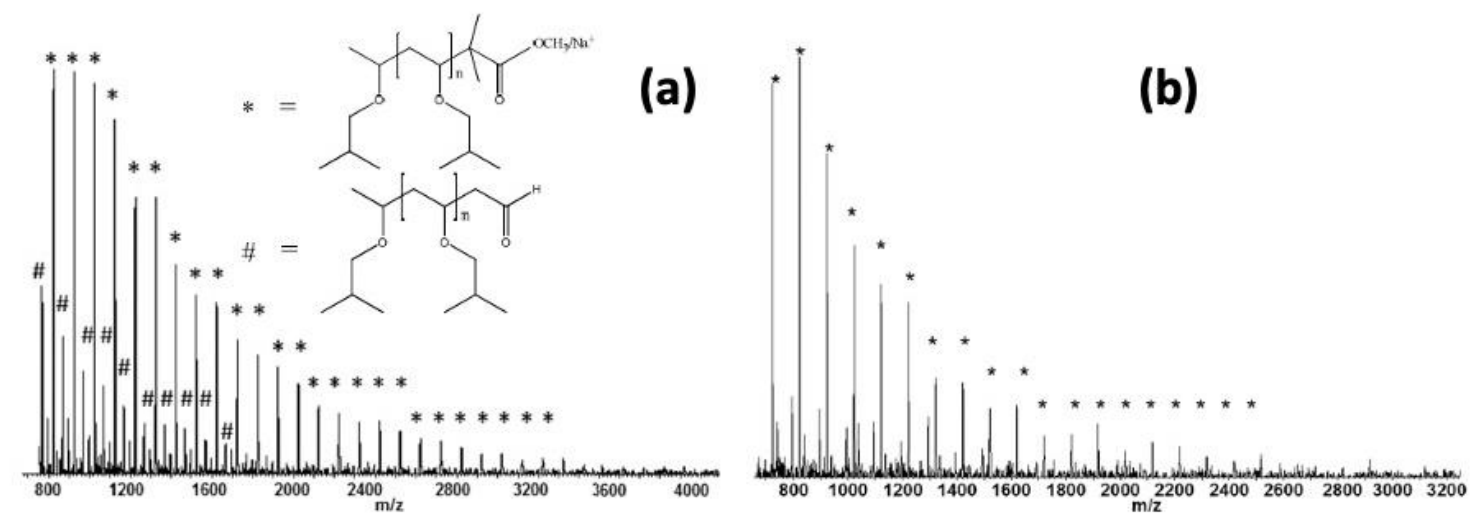

Figure 6. MALDI ToF mass spectra derived from: (a) iBVE polymerised at $-26{ }^{\circ} \mathrm{C}$ (b) $i$ BVE polymerised at $-78^{\circ} \mathrm{C}$ $\left([i B V E]=\left(1.0 \mathrm{~mol} \mathrm{dm}^{-3}\right),\left[i \mathrm{BVE}: \mathrm{HCl}: \mathrm{SnCl}_{4}\right]=0.01 \mathrm{~mol} \mathrm{dm}{ }^{-3},[1]=0.03 \mathrm{~mol} . \mathrm{dm}-3\right)$. Ion series indicated with $*$ or \#.

Figure 7(b) shows that, as expected the final monomer conversion decreased as [1] was increased. As discussed for MVE the decrease in both $M_{n}$ and final conversion with increasing [1] provide good evidence for alkylation of 1 on the same timescale as propagation rather than alkylation that occurs after propagation.

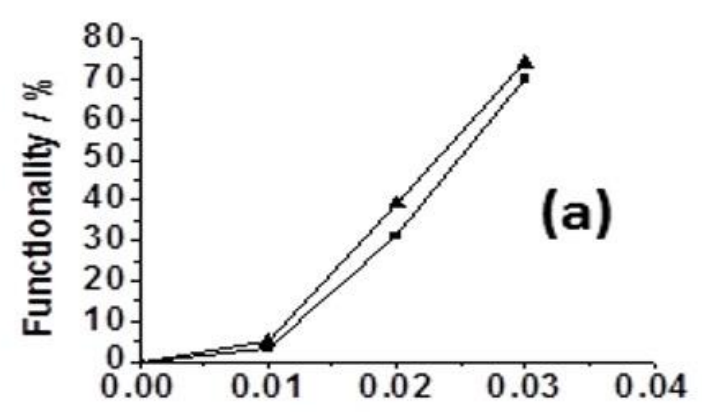

$[1] / \mathrm{mol} \mathrm{d} \mathrm{m}^{-3}$

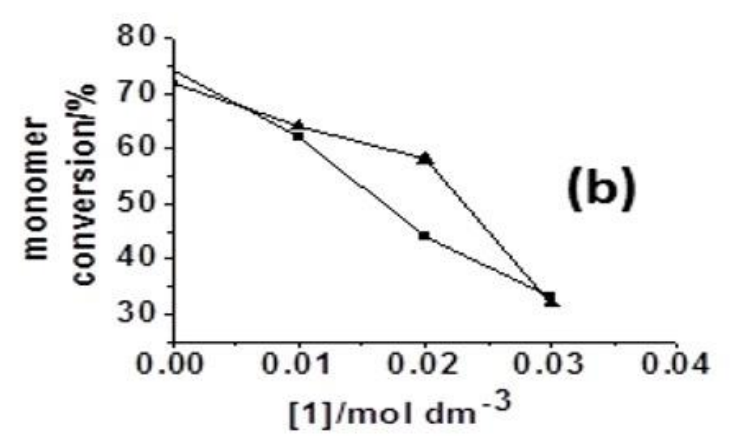

$[1] / \mathrm{mol} \mathrm{dm}^{-3}$

Figure 7. (a) Functionality of poly(iBVE) prepared with various initial [1]. (b) iBVE conversions for polymerization of $i \mathrm{BVE}\left(1.0 \mathrm{~mol} \mathrm{dm} \mathrm{m}^{-3}\right)$ in the presence of 1 initiated by $i \mathrm{BVE}: \mathrm{HCl}: \mathrm{SnCl}_{4}\left(0.01 \mathrm{~mol} \mathrm{dm}^{-3}\right)$. Reaction time 1.5 hours at $-26^{\circ} \mathrm{C}$ or $-78^{\circ} \mathrm{C} \boldsymbol{\Delta}$.

Further optimisation of the polymerisation of $i B V E$ was carried out using an initial concentration of 0.38 $\mathrm{mol} \mathrm{dm}{ }^{-3}$ at $-78,-15,0$ and $20^{\circ} \mathrm{C}$. MALDI-ToF mass spectra from these polymerisations are shown in figure 8. At $-78{ }^{\circ} \mathrm{C}$, the dominant ion distribution in these data was described by $m / z=n 100.1+(23+202.2)$ and this distribution amounted to more than $95 \%$ of the chains. Figure 8 also shows spectra from other reaction temperatures and at $-15,0$ or $20^{\circ} \mathrm{C}$ significant fractions of the ions were derived from distributions of chains with other end groups. Notably at $20^{\circ} \mathrm{C}$ the distribution from the target ions, with $\mathrm{H}$ at the $\alpha$-end and methyl(2, 2 dimethyl) ethanoate at the $\omega$-end, was a minor component of the overall mass spectrum. At $20^{\circ} \mathrm{C}$ the major distribution of ions was $m / z=\mathrm{n} 100.1+(23+146.1)$ or $(23+46.1)$, which (as previously reported $\left.{ }^{30}\right)$ can $^{2}$ be assigned to polymers with $-\mathrm{CH}_{2} \mathrm{CH}_{2} \mathrm{OH}$ and $-\mathrm{H}$ groups at the $\omega$ and $\alpha$-chain ends respectively. Also, at -15 and and $0{ }^{\circ} \mathrm{C}$ other distributions of ions were observed that were described by $m / z=100.2+(23+74.3)$ and $m / z=n 100.0+(23+29.3)$. Both of these ion series have been assigned previously by us and are derived from chain ends that are capped with the isobutoxy and methoxy groups respectively. ${ }^{30}$ 
35
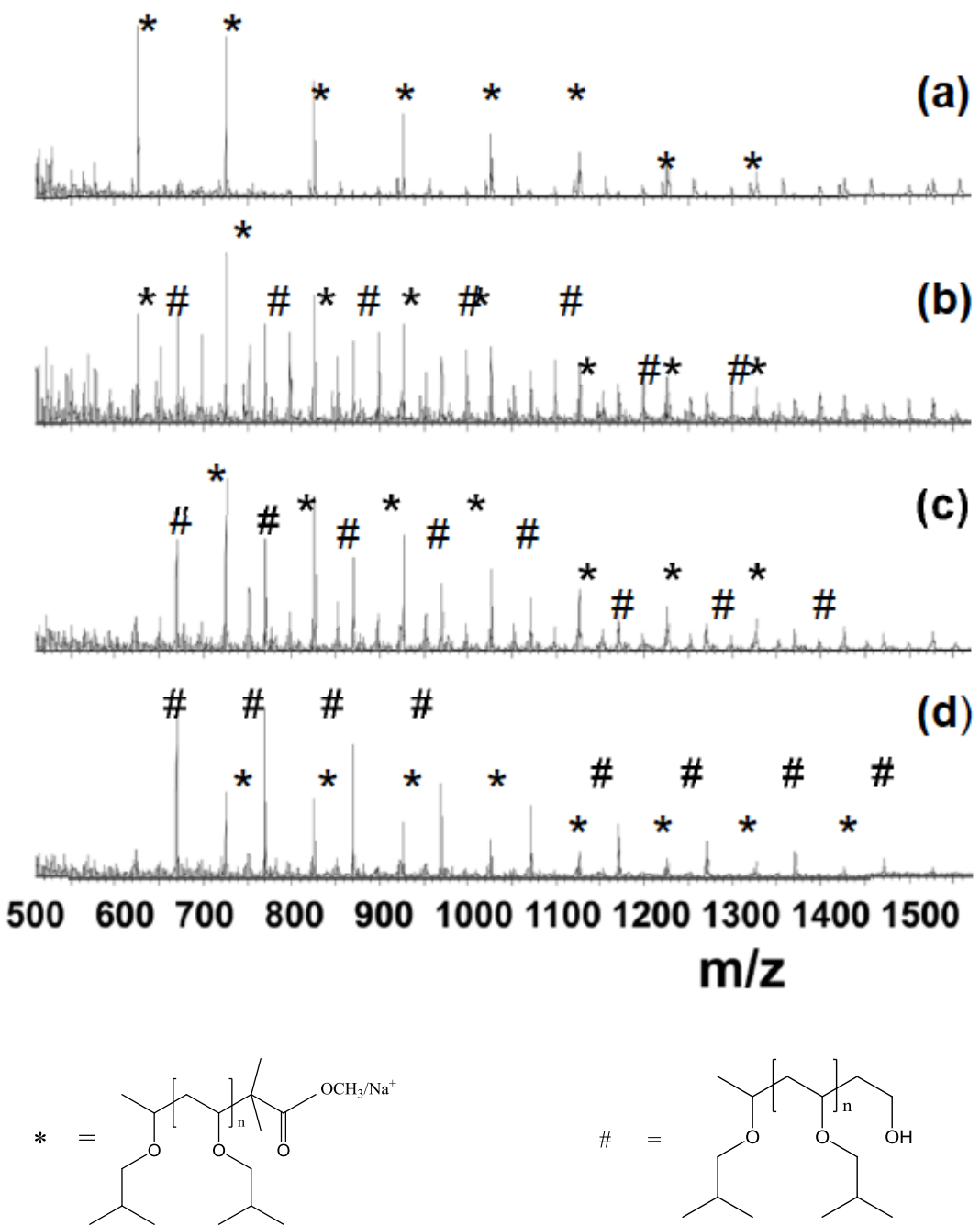

Figure 8. MALDI ToF mass spectra for polymerization of $i B V E\left(0.38 \mathrm{~mol}^{-3} \mathrm{dm}^{-3}\right)$ in the presence of 1 initiated by iBVE: $\mathrm{HCl}: \mathrm{SnCl}_{4}\left(0.038 \mathrm{~mol} . \mathrm{dm}^{-3}\right)$. Reaction time 1 hour. Polymerisation temperatures:(a) -78 ; (b) -15 ; (c) 0 and (d) $20^{\circ} \mathrm{C}$. Ion series indicated with * or \#.

$A b$ intio cationic polymerisations of $i B V E$ in the presence of $\mathrm{TiCl}_{4}$ as a Lewis acid were carried out at -26 and $-78^{\circ} \mathrm{C}$ with differing concentrations of 1 . The resultant molar masses and dispersities are shown in Figure 9. 

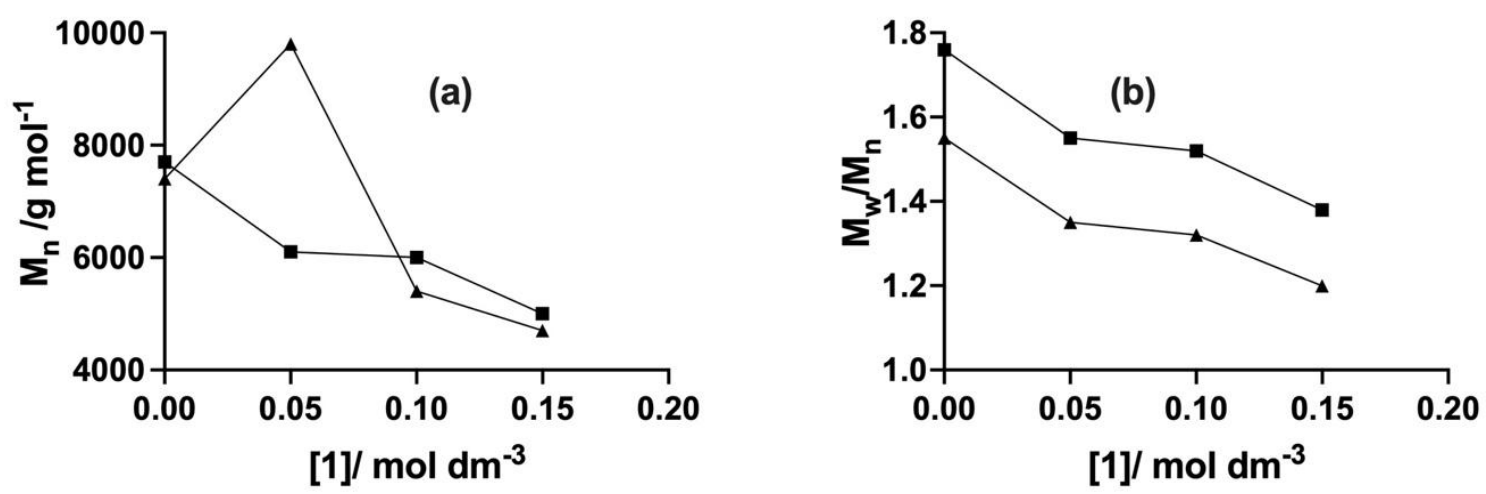

Figure 9. Molar mass (SEC) data for polymerisation of $i B V E\left(1.0 \mathrm{~mol} \mathrm{dm}^{-3}\right)$ in the presence of 1 initiated by iBVE: $\mathrm{HCl}: \mathrm{TiCl}_{4}\left(0.01 \mathrm{~mol} \mathrm{dm}{ }^{-3}\right)$. Reaction time 1.5 hours at $-26^{\circ} \mathrm{C}$ or $-78^{\circ} \mathrm{C} \mathbf{\Delta}$.

Figure 9 shows that at both -26 and $-78^{\circ} \mathrm{C} M_{n}$ was reduced as [1] increased. However, unexpectedly there was an increase at a molar ratio of initiator: 1 of $1: 5$ at $-78^{\circ} \mathrm{C}$. An increase in $M_{n}$ would occur in this system if the concentration of initiator was reduced as initiator reacted with $\mathbf{1}$ in a similar time frame to addition to the monomer alkene group. However, the data suggest that at higher concentrations of 1 the rate of alkylation of 1 by the propagating chain increased and $M_{n}$ decreased. On the otherhand Figure $9 \mathrm{~b}$ showed that the dispersity in molar mass reduced as [1] was increased, as expected in polymerisations in which alkylation of [1] occurred in the same timescale as propagation. A typical ${ }^{1} \mathrm{H} n m r$ spectrum is shown in Figure 10 . The spectra provided evidence for the $\alpha-\mathrm{H}$ and the methyl groups from the $\omega$-methyl-(2, 2 dimethyl) ethanoate between 1 and $1.2 \mathrm{ppm}$. Also, the methoxy moiety from this end group was observed at $3.70 \mathrm{ppm}$.

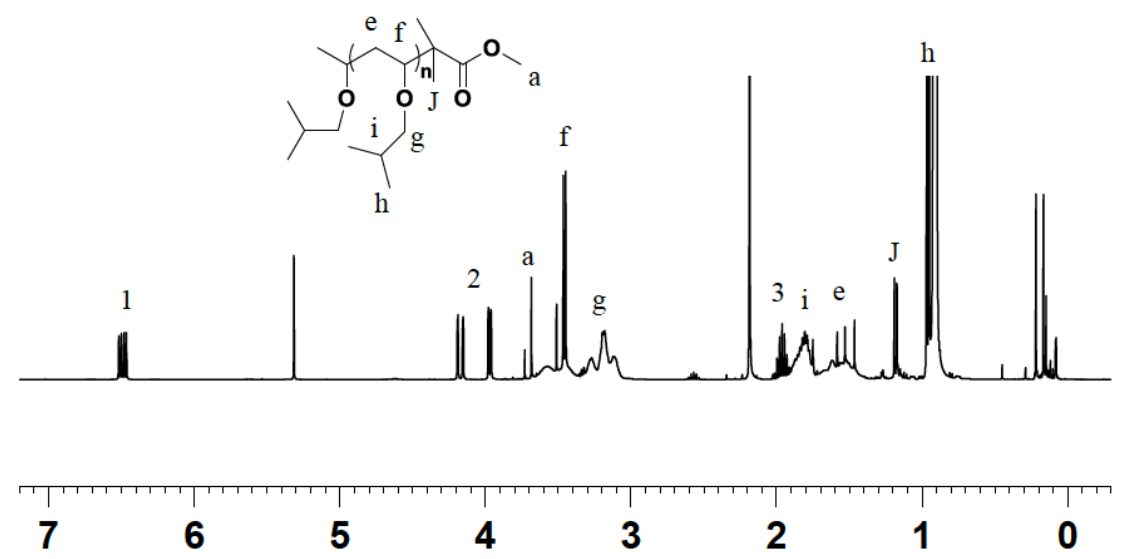

Figure 10. A Typical ${ }^{1} \mathrm{H}$ NMR spectrum of polyiBVE synthesised in the presence of 1 . Peaks 1,2 and 3 are from residual monomer. 


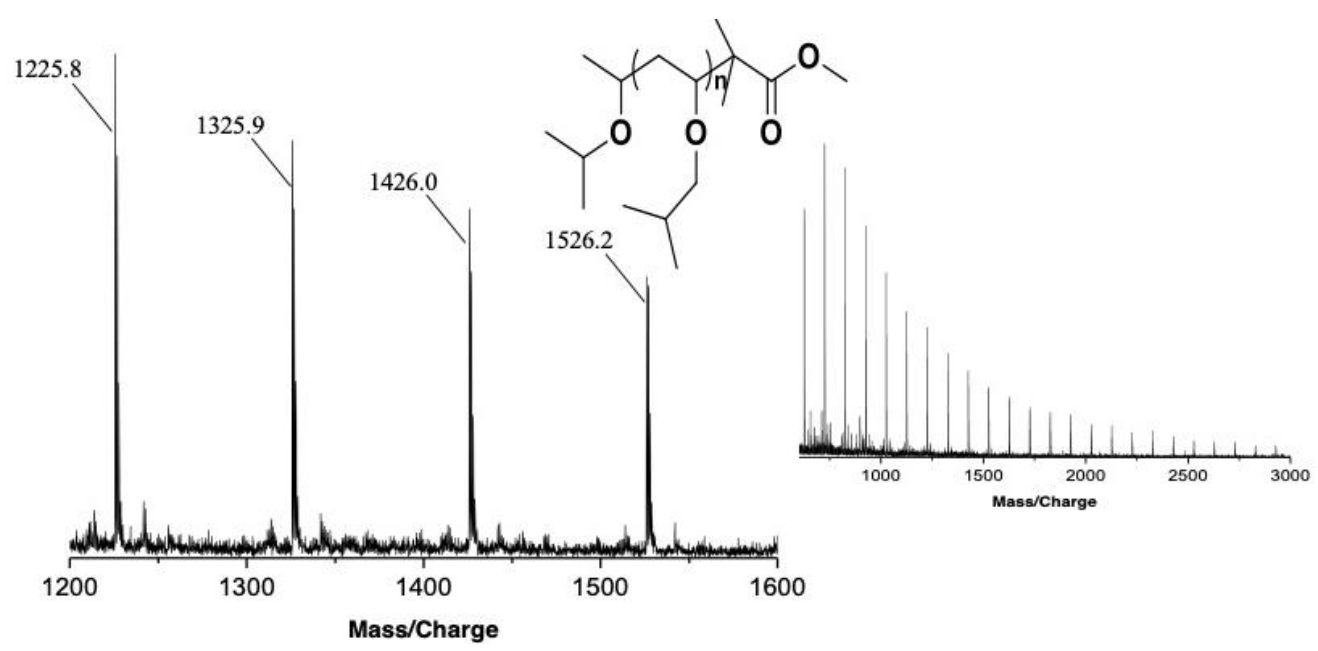

Figure 11. MALDI-TOF-MS spectrum with the determined chain end groups for polyiBVE $0.15 \mathrm{~mol}^{\mathrm{d} \mathrm{dm}^{-3}}$ obtained by dried droplet method using Dithranol as a matrix, sodium iodide as salt and THF as the carrier solvent.
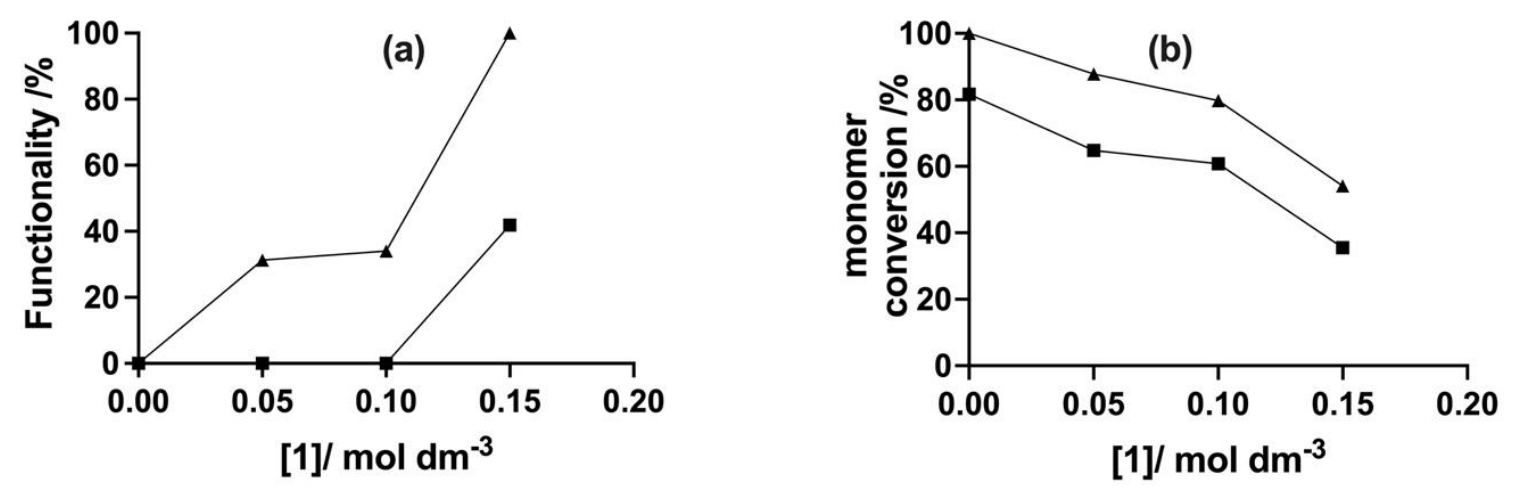

Figure 12. (a) Functionality of polyiBVE prepared with various initial [1]. (b) iBVE conversions for polymerisation of $i B V E\left(1.0 \mathrm{~mol} . \mathrm{dm}^{-3}\right)$ in the presence of 1 initiated by $i \mathrm{BVE}: \mathrm{HCl}: \mathrm{TiCl}_{4}\left(0.01 \mathrm{~mol}^{\mathrm{d}} \mathrm{dm}^{-3}\right)$. Reaction time 1.5 hours at $-26^{\circ} \mathrm{C} \mathbf{m}$ or $-78^{\circ} \mathrm{C} \mathbf{A}$.

From Figure 12 it is clear that addition of 1 at $-26{ }^{\circ} \mathrm{C}$ did not result in functionalisation of the chain ends, although $40 \%$ of the chain ends were found to be functionalised at [1] $=0.15 \mathrm{~mol} \mathrm{dm}^{-3}$. Functionalisation was much more effective at $-78^{\circ} \mathrm{C}$ because the rates of termination by elimination are much reduced at lower temperatures. The final monomer conversions are shown in Figure $12 \mathrm{~b}$ and as expected the monomer conversions decreased as [1] was increased.

\section{Conclusions}

Poly(vinyl ether)s have been prepared with ester end groups using non-living ab initio cationic polymerisations, in which alkylation of a silyl ketene acetal occurred simultaneously with propagation. It was shown that optimisation of the reaction temperature, monomer concentration and concentration of the silyl ketene acetal was required to achieve high degrees of chain end functionality. However, provided these 
parameters were carefully considered it was possible to produce reactive polymers with useful ester end groups in high yield and with almost all of the end groups containing the ester moiety. For the polymerisation of both MVE and $i B V E$ it was found that high end group functionalities were obtained in polymerisations carried out at $-78{ }^{\circ} \mathrm{C}$ using $\mathrm{TiCl}_{4}$ as Lewis acid. PolyiBVE could also be prepared using $\mathrm{SnCl}_{4}$ as Lewis acid at a monomer concentration of $0.38 \mathrm{~mol} \mathrm{dm}^{-3}$ but at $1.0 \mathrm{~mol} \mathrm{dm}$ chains with only as maximum of $70 \%$ esters at the chain ends were produced.

\section{Experimental Section}

General. MVE (98\% Aldrich) was purified by passing the gaseous monomer through a calcium hydride column and condensed at $-80^{\circ} \mathrm{C}$. iBVE (99\%, Aldrich) was dried overnight with anhydrous sodium sulphate and distilled before use. $\mathrm{N}$-hexane (99\%, Aldrich) was refluxed over calcium hydride for two hours and distilled just before use. Sulphuric acid (concentrated) and sodium chloride (AR grade, BDH) were used as received. Dichloromethane (DCM) (99.6\%, Aldrich) was refluxed over $\mathrm{CaH}_{2}$ and then distilled just before use. $\mathrm{SnCl} 4$ and $\mathrm{TiCl}_{4}\left(1.0 \mathrm{~mol}\right.$. $\mathrm{dm}^{-3}$ solution in DCM, Aldrich) were used as received. 1-methoxy-2-methyl-1(trimethylsilyloxy)propene, 1, (95\%, Lancaster) was purified by fraction distillation under reduced pressure.

\section{Synthesis of $\mathrm{HCl}-$ iBVE adduct}

The reaction was carried out in a pre-sealed three-neck round bottom flask under dry nitrogen atmosphere. Dry nitrogen was produced by passing the gas through a drying column filled with indicated drierite. iBVE (in $\mathrm{n}$-hexane, $1.0 \mathrm{~mol}$. $\mathrm{dm}^{-3}$ ) was added to the flask. $\mathrm{HCl}$ gas was generated by dropping concentrated sulphuric acid into powdered sodium chloride and then dried by passing through concentrated sulphuric acid, activated charcoal and dry silica gel. The gaseous $\mathrm{HCl}$ was passed through iBVE solution and the reaction was continued for one hour at $0{ }^{\circ} \mathrm{C}$. The excess $\mathrm{HCl}$ in the reaction mixture was removed by bubbling dry nitrogen gas through it. The quantitative formation of the pure adduct was confirmed by ${ }^{1} \mathrm{H} N M R$ and the concentration of $\mathrm{HCl}-i \mathrm{BVE}$ adduct was measured by the Volhard method. The solution was sealed into a brown bottle and stored in a freezer.

\section{Preparation of ester ended poly(methyl vinyl ether)}

Polymerisation of MVE was carried out in a three-neck round bottom flask under dry nitrogen atmosphere in DCM. Polymerisation was initiated by introducing $\mathrm{TiCl}_{4}$ in $\mathrm{DCM}$ solution to the solution containing $\mathrm{MVE}, \mathrm{HCl}-$ iBVE adduct (as an initiator) and 1 at $-26{ }^{\circ} \mathrm{C}$ and $-78{ }^{\circ} \mathrm{C}$. The reaction mixture was stirred for 1.5 hours. The reaction was quenched with $2.0 \mathrm{~mol} . \mathrm{dm}^{-3}$ ammonia solution in methanol and diluted by addition of DCM. The polymer solution was washed sequentially with $2 \% \mathrm{HCl}$ and deionised water (both below $10^{\circ} \mathrm{C}$ ) to remove the titanium or tin containing residues. The solvent and unreacted reagents were removed by rotary-evaporation under reduced pressure and vacuum dried over-night to give the product.

\section{Preparation of poly(isobutyl vinyl ether) with an ester end group}

Polymerisation of iBVE was carried out in a three-neck round bottom flask under dry nitrogen atmosphere in DCM. Polymerisation was initiated by introducing $\mathrm{SnCl}_{4}$ or $\mathrm{TiCl}_{4}$ in $\mathrm{DCM}$ solution to the solution containing $i \mathrm{BVE}, \mathrm{HCl}-\mathrm{BBVE}$ adduct (as an initiator) and $\mathbf{1}$. The reaction mixture was stirred for 1.5 hours and then quenched with 2.0 mol. $\mathrm{dm}^{-3}$ ammonia solution in methanol and diluted by addition of DCM. The polymer solution was washed sequentially with $2 \% \mathrm{HCl}$ and deionised water (both below $10^{\circ} \mathrm{C}$ ) to remove the titanium containing residues. The solvent and unreacted reagents were removed by rotary-evaporation under reduced pressure and vacuum dried over-night to give the product. 


\section{Polymer characterisation}

${ }^{1} \mathrm{H}$ NMR spectra were recorded on a Bruker $250 \mathrm{MHz}$ instrument at ambient temperature in deuterated chloroform. SEC measurements were carried out using a RI detector at ambient temperature with THF as the solvent and toluene as a flow marker. Polymer laboratories gel $2 \times 60 \mathrm{~cm}$ low molecular weight columns were used, calibrated against polystyrene standards. Sample concentration was $2.5 \mathrm{mg} \mathrm{cm}^{-3}$. MALDI-TOF mass spectra were obtained using a TofSpec $2 \mathrm{E}$ instrument, Micromass, using dithranol as the matrix. The following parameters were used to analyse the polymer samples: Instrument voltage: $20 \mathrm{KV}$, sampling rate: $500 \mathrm{MHz}$, pulse time: 39 , pulse voltage: $2471 \mathrm{~V}$, detector voltage: $1689 \mathrm{~V}$, cationisation agent: Nal.

The end group masses were obtained from the MALDI-ToF mass spectra by plotting $\mathrm{m} / z$ against $\mathrm{n}$. Where $\mathrm{n}$ is the degree of polymerisation. Then the end group masses were obtained by linear regression from

$m / z=n M_{r}+(C+r)$

Equation 1

Where $\mathrm{M}_{\mathrm{r}}=$ monomer repeat mass; $\mathrm{C}=$ atomic mass of the cationising ion $(\mathrm{Na}+$ or $\mathrm{K}+)$ and $\mathrm{r}=$ the sum of both end group masses.

Functionality was determined from the MALDI ToF mass spectra by obtaining the area of ion peaks corresponding to the target polymers within the total peak area \pm of $m / z 20$ of the apex of the peak. For each target ion peak this produced a set of functionalities, $F_{i}$ corresponding to all of the degrees of polymerisation in the sample. The average functionality was then obtained by calculating the number average of these peaks. That is the percent functionality is given by:

$F_{n}=100 \times \sum F_{i} A_{i} / \sum A_{i}$

Equation 2

Where, $F_{i}=$ the functionality of the ith ion peak and $A_{i}=$ the area of ith peak.

\section{References}

1. Sun, Y.; Collett, J.; Fullwood, N.J.; MacNeil, S.; Rimmer, S.Biomaterials, 2007, 28, 661. https://doi.org/10.1016/i.biomaterials.2006.09.024

2. Collett, J.; Crawford, A.; Hatton, P.V.; Geoghegan, M.; Rimmer, S. J. Roy. Soc.-Interface, 2007, 4, 117. https://doi.org/10.1098/rsif.2006.0158

3. Rimmer, S.; Mohd. Ramli, A.N.; Lefèvre, S. Polymer, 1996, 37, 4135.

https://doi.org/10.1016/0032-3861(96)00253-4

4. The Polyurethanes Book, D.; Lee, S. Eds. Wiley: New York, 2003. ISBN: 978-0-470-85041-1

5. Lo Verso, F.; Likos, C.N. Polymer, 2008, 49, 1425. https://doi.org/10.1016/i.polymer.2007.11.051

6. Collins, S.; Rimmer, S. React. Funct. Polym., 2006, 66, 177. https://doi.org/10.1016/i.reactfunctpolym.2005.07.014

7. Pernecker, T.; Kennedy, J.P.; Ivan, B. Macromolecules, 1992, 25, 1642. https://doi.org/10.1021/ma00032a004

8. Satoh, K.; Katayama, H.; Kamigaito, M.; Sawamoto, M. ACS Symp. Ser., 1997, 665, 106. https://doi.org/10.1021/bk-1997-0665.ch010

9. Miyamoto, M.: Sawamoto, M.; Higashimura, T. Macromolecules, 1984, 17, 265. 
https://doi.org/10.1021/ma00133a001

10. Matyjaszewski, K. Macromol. Symp., 1988, 13/14, 433.

https://doi.org/10.1002/masy.19880130131

11. Pernecker, T.; Kennedy, J.P.; Ivan, B. Macromolecules, 1992, 25, 1642.

https://doi.org/10.1021/ma00032a004

12. R. Faust, J.P. Kennedy, Polym. Bull., 1986, 15, 317.

https://doi.org/10.1007/BF00254850

13. Lang, W.; Rimmer, S. Macromol. Rap. Comm., 2001, 22, 194.

https://doi.org/10.1002/1521-3927(200102)22:3<194::AID-MARC194>3.0.CO;2-C

14. Sarker, P.K.; Rimmer, S. Macromol. Chem. \& Phys., 2005, 206, 1280.

https://doi.org/10.1002/macp.200500128

15. Lang, W.; Sarker, P.K.; Rimmer, S. Macromol. Chem. \& Phys., 2004, 205, 1011.

https://doi.org/10.1002/macp.200300198

16. England, R.M.; Rimmer, S. Chem. Commun., 2010, 46, 5767.

https://doi.org/10.1039/c0cc01705a

17. Fukui, H.; Deguchi, T.; Sawamoto, M.; Higashimura, T. Macromolecules, 1996, $29,1131$. https://doi.org/10.1021/ma946432+

18. Fukui, H.; Yoshihashi, S.; Sawamoto, M.; Higashimura, T. Macromolecules, 1996, $29,1862$. https://doi.org/10.1021/ma946436e

19. Fukui, H.; Sawamoto, M.; Higashimura, T. Macromolecules, 1996, 28, 3756. https://doi.org/10.1021/ma00115a002

20. Fukui, H.; Sawamoto, M.; Higashimura, T. Macromolecules 1994, $27,1297$. https://doi.org/10.1021/ma00084a002

21. Fukui, H.; Sawamoto, M.; Higashimura, T. Macromolecules 1993, 26, 7315. https://doi.org/10.1021/ma00078a030

22. Tasdelen, M. A.; Kahveci, M. U.; Yagci, Y. Progr. Polym. Sci. 2011, 36, 455. https://doi.org/10.1016/i.progpolymsci.2010.10.002

23. Rajanbabu, T.V. J. Org. Chem. 1984, 49, 2083. https://doi.org/10.1021/jo00186a001

24. Mayr, H.; Bug, T.; Gotta, M.F.; Hering, N.; Irrgang, B.; Janker, B.; Kempf, B.; Loos, R.; Ofial, A. R.; Remennikov, G.; Schimmel , H. J. Am. Chem. Soc., 2001, 123, 9500.

https://doi.org/10.1021/ja010890y

25. Burfeindt, J.; Patz, M.; Müller, M.; Mayr, H. J. Am. Chem. Soc., 1998, 120, 3629. https://doi.org/10.1021/ja974003w

26. Van Durme, K. ; Van Mele, B.; Bernaerts, K. V.; Verdonck, B.; Du Prez, F. E. J Polym Sci Part B: Polym. Phys. 2006, 44, 461.

https://doi.org/10.1002/polb.20710

27. Subira, F.; Sauvet, G.; Vairon, J-P.; Sigwalt, P. J. Polym. Sci. Symp. 1976, 56, 221. https://doi.org/10.1002/polc.5070560123

28. Subira, F.; Vairon, J-P.; Sigwalt, P. Macromolecules, 1988, 21, 2339. https://doi.org/10.1021/ma00186a007

29. Ohmura, T.; Sawamoto, M.; Higashimura, T. Macromol 1994, 273714. https://doi.org/10.1021/ma00092a006

30. Lang, W.; Rimmer, S. Macromol. Symp., 2002, 184, 311. 
https://doi.org/10.1002/1521-3900(200208)184:1<311::AID-MASY311>3.0.CO;2-8

31. Katayama, H.; Kamigaito, M.; Sawamoto, M. J. Polym. Sci. A: Polym. Chem., 2001, 39, 1249. https://doi.org/10.1002/pola.1102

32. Katayama, H.; Kamigaito, M.; Sawamoto, M. , J Polym Sci A: Polym Chem., 2001, 39, 1258. https://doi.org/10.1002/pola.1103

This paper is an open access article distributed under the terms of the Creative Commons Attribution (CC BY) license (http://creativecommons.org/licenses/by/4.0/) 